\title{
Experimental Evidence on Connections between Speech and
} Music : Possible Applications on Learning

\section{Huotilainen, Minna}

Brill

2021

Huotilainen, M \& Kujala , T 2021 , Experimental Evidence on Connections between Speech and Music : Possible Applications on Learning . in E Kuusisto, M Ubani , P Nokelainen \& A Toom (eds), Good Teachers for Tomorrow's Schools : Purpose, Values, and Talents in Education . Moral Development and Citizenship Education, vol. 16 , Brill, Leiden, pp. 313-330 . https://doi.org/10.1163/9789004465008_017

http://hdl.handle.net/10138/339691

https://doi.org/10.1163/9789004465008_017

acceptedVersion

Downloaded from Helda, University of Helsinki institutional repository.

This is an electronic reprint of the original article.

This reprint may differ from the original in pagination and typographic detail.

Please cite the original version. 


\title{
Experimental evidence on connections between speech and music - possible applications on learning
}

\author{
Minna Huotilainen ${ }^{1,2}$ and Teija Kujala ${ }^{2}$ \\ CICERO Learning, Faculty of Educational Sciences, University of Helsinki ${ }^{1}$ \\ Cognitive Brain Research Unit, Department of Psychology and \\ Logopedics, Faculty of Medicine, University of Helsinki
}

\begin{abstract}
Some researchers consider music and speech as alternative means of communication, containing somewhat similar but still distinct acoustic features to carry information from the player, singer, or speaker to the listener. These low-level similarities in speech and music as acoustic signals form the starting point for experimental research comparing automatic neural processes in perceiving music and speech. Importantly, there is also evidence that learning occurs in these low-level neural processes due to exposure and training. We review the influence of music on language systems. We also discuss some recent evidence showing that musical training can have a positive effect on speech perception and neural processing of speech signals. Finally, we propose some possible applications of music interventions on learning of speech perception in early childhood education and in schools.
\end{abstract}

\section{Keywords}

Speech - Music - Brain - Learning - Dyslexia - Hearing Impairment 
There are notable similarities between speech and music on several levels of processing. The power of using music as a means of education depends partially on these similarities. Educators have named musical skills as one of the subjects where fixed mindsets are more frequent: pupils with a fixed mindset are more likely to talk about "musical talent" and to interpret their own mistakes as a lack of musical ability rather than lack of effort or time spent practicing (Dweck, 2006). This paper discusses the experimental and especially neural foundations of the applicability of music in education, namely, the similarities of speech and music, brain plasticity and transfer effects, as well as experimental evidence of the use of music in special education. Finally, we also present some thoughts on how teachers can apply this knowledge in their work in using music as a means of education.

\section{$1 \quad$ Key similarities between processing of speech and music}

The shared properties of language and music have been investigated on several domains, starting from low-level acoustic similarities to structural similarities and even shared evolutionary origins (Patel, 2007). Both speech and music are learned through interactions with other individuals, utilizing audition as the main channel but also strongly influenced by non-vocal communication, such as facial and bodily expressions and movements. They consist of successive acoustic events that unfold over time, both operating in rhythmic, tonal and timbre domains. Further, both speech and music use high-level hierarchical structures of combinations of these acoustic events, thus forming new representations derived from the combinations. In speech, an example would be combining phonemes or syllables in a row to form words and sentences with meaning, while in music, melodies are formed from successive tones and chords are formed from simultaneous tones (see Figure 1).

For decades, the low-level similarities in the mode of expression of speech and music have inspired teachers and educators to investigate the possibilities of music in helping children's language development and learning. Even more evidence on the shared mechanisms was found after it became possible to study the neural correlates of speech and music perception. For example, although some studies indicate lateralization of brain areas, i.e., stronger responses in the left temporal lobe for speech and in the right for music (Zatorre et al., 2002), the very basic acoustic analysis of both speech and music is carried out in overlapping temporal- 
lobe cortical areas. Further, violations of structure, i.e., ungrammatical words in speech or out-of-key notes in music, were found to give rise to similar changes in the event-related potential (ERP) called P600 (Patel et al., 1998). Functional magnetic resonance imaging (fMRI) studies have identified overlapping cortical areas in the inferior frontal gyrus to be responsible for the processing of both musical and linguistic structure (Tillman et al., 2003, Friederici et al., 2003, see also Rogalsky and Hickok, 2010, and Peretz et al., 2015, for critical discussions on studies assessing musical and linguistic structural processing). Naturally, these high-level similarities between speech and music have also inspired educators to use music as a teaching method outside the musical domain and especially for language learning.

Currently, in the light of acoustic, behavioral and neural investigations, there is a strong consensus of the close connections between speech and music perception. The most overwhelming evidence comes from the lowlevel acoustic features such as similarities in the perception of musical timbres and phonemes, similarities in perceiving melodies and speech intonation patterns, and overlapping requirements for memory and attentive processes due to the unfolding-in-time nature of both speech and music. These similarities can help us understand how, practically, musical activities could support pupils with speech- and language-related problems. The process of achieving a positive transfer effect from practicing musical activities to learning speech- and language-related skills is dependent on the capacity of the auditory system to change after exposure, training and teaching, efficiently occurring in active interaction between human beings. This neural learning-related process is called brain plasticity. Plasticity, the brain's ability to change, is a core mechanism which is always involved when an individual learns something, whether it is new melodies, phonemes, or some complex knowledge at school. Below we review some of the main findings specifically related to plasticity in the auditory system, which has a central role in music and language processing.

\section{$2 \quad$ Plasticity and learning in the auditory system}

There is a broad consensus that the auditory system of the human brain can change its function and structure according to exposure (spending time in environments where one is exposed to certain sounds), training (engaging in tasks for a long enough time) and teaching on a larger scale (being given information and activities by a teacher or a coach, being 
supported and scaffolded towards expertise via tasks and training). Plasticity of the auditory system can be investigated on several levels ranging from the cellular, synaptic, and network levels up to systems level. For the purpose of this text, it is most beneficial to use the framework of cognitive neuroscience where brain plasticity is often described as measurable structural and/or functional changes in the brain that are associated with changes in behavior and are caused by exposure or training.

In the area of auditory-system plasticity, two time scales are usually separated (Galván, 2010). Long-term plasticity involves effects occurring on the time scale of years. For example, being exposed to a certain native language for decades results in plastic changes in the auditory system, making it easy to recognize the phonemes of the native language. Shortterm plasticity, however, would occur in time scales from minutes to weeks. For example, in order to learn to sing a new simple song one might need to practice it for a few minutes per day for a few weeks. Thereafter, the brain would automatically react to hearing any modified notes in this simple melody. Typically, long-term plasticity is studied in cross-sectional studies (comparing two groups of people who have had different types of long-term exposure or training), although longitudinal follow-up studies also exist. Short-term plasticity is typically studied in experiments where pre- and post-tests are administered and training occurs between them. It is often not possible to use double-blind randomized controlled trials, but forming matched intervention groups is considered to be important in order to control for family background and genetic factors.

The auditory system shows plasticity to music even without any musical training, merely due to exposure to a certain musical culture. For example, tonality (Toiviainen and Krumhansl, 2003) and meter (Hannon et al., 2004) are musically relevant phenomena that the auditory system is also shown to be sensitive to in individuals without any musical training. Our innate musicality allows our brains to form models of tone and meter simply when exposed to a certain musical culture. Plasticity resulting from music exposure is even observed in animal studies (Rickard et al., 2005), showing that no prior knowledge or music training is required for the beneficial structural and functional music effects to emerge.

Musical training can influence the auditory system greatly and at several levels. At the brainstem, which is a very early part of the auditory pathway, changes in response patterns have been observed due to musical training (Wong et al., 2007). The changes at this level allow the auditory system to extract information from sounds more accurately. This was proposed to be one of the mechanisms via which musical training 
affects the perception of all sounds, including speech sounds. Further, in the primary and surrounding auditory cortices, musical training was found to enhance neural structure and function (Schneider et al., 2002, Bermudez et al., 2009). Some studies have shown that the plasticity extends to higher-order cortical areas (Lappe et al., 2008).

Like music, language learning can also occur through passive exposure and by actively training language functions. For instance, it was shown that representations of new word-forms, that is, new words that do not have pre-existing meanings, are formed when the individual is exposed to them even when not paying attention to the stimuli (Shtyrov et al., 2010; Kimppa et al., 2018). Furthermore, these studies found that the representations are formed very rapidly, in less than 15 minutes in adults (Shtyrov et al., 2010) and within 6 minutes in children (Kimppa et al., 2018).

These findings on automatic and rapid learning of words have changed our view on language learning mechanisms. Learning of new languages usually requires extensive training. In grammar learning, which is a central task in school in language-learning classes, one has to engage attention and memory mechanisms to achieve the proficiency of the new language. The acquisition of the phonology of a new language often calls for effort, and there can be a large variation between individuals in how they master the pronunciation even after extensive training.

FIGURE 1 Key similarities and differences between the acoustic signals and expressive features of speech and music. At the lowest level of expression, both speech and music use frequency content and timing of sounds as features. This similarity opens the 
possibility to direct transfer effects: skills learned in musical activities are directly benefitting the perception of frequency content and sound timing in speech perception. For the mid-level features, differences are obvious, reflected in the different processing systems of speech and musical sounds in the brain. Finally, similarities occur at the highest level, where both speech and music use structured, meaning-loaded expressions and use similar acoustic characteristics to express emotions.

\begin{tabular}{|c|c|c|c|}
\hline \multicolumn{2}{|c|}{ Features specific to music } & \multicolumn{2}{|c|}{ Features specific to speech } \\
\hline $\begin{array}{l}\text { Features specific } \\
\text { to music, distant } \\
\text { from speech }\end{array}$ & $\begin{array}{l}\text { Features specific } \\
\text { to music, close to } \\
\text { speech }\end{array}$ & $\begin{array}{l}\text { Features specific } \\
\text { to speech, close } \\
\text { to music }\end{array}$ & $\begin{array}{l}\text { Features specific } \\
\text { to speech, distant } \\
\text { from music }\end{array}$ \\
\hline \multicolumn{4}{|c|}{ High-level features } \\
\hline \multicolumn{2}{|c|}{$\begin{array}{l}\text { - Building emotional and } \\
\text { sometimes cognitive } \\
\text { content and meaning } \\
\text { via music }\end{array}$} & \multicolumn{2}{|c|}{$\begin{array}{l}\text { - Building cognitive and } \\
\text { often emotional content } \\
\text { and meaning via speech }\end{array}$} \\
\hline \multicolumn{4}{|c|}{ Mid-level features } \\
\hline $\begin{array}{l}\text { - Harmony and } \\
\text { scales } \\
\text { - Chord structure } \\
\text { and progression }\end{array}$ & & & $\begin{array}{l}\text { - Semantics, i.e., } \\
\text { specific meaning } \\
\text { of words } \\
\text { - Grammar }\end{array}$ \\
\hline \multicolumn{4}{|c|}{ Low-level features } \\
\hline \multicolumn{2}{|c|}{$\begin{array}{l}\text { - Fundamental frequency / } \\
\text { pitch } \\
\text { - Timbre: recognition of a } \\
\text { musical instrument on the basis } \\
\text { of spectral content and fast } \\
\text { spectral changes } \\
\text { - Timing: using rhythm and } \\
\text { sound duration as expressive } \\
\text { elements } \\
\text { - Memory requirement: keeping } \\
\text { previous tones in memory in } \\
\text { order to combine them into a } \\
\text { coherent melody }\end{array}$} & \multicolumn{2}{|c|}{$\begin{array}{l}\text { - Fundamental frequency / } \\
\text { pitch } \\
\text { - Timbre: recognition of a } \\
\text { phoneme on the basis of } \\
\text { formants, i.e., spectral content, } \\
\text { as well as fast spectral changes } \\
\text { - Timing: using sound duration } \\
\text { and sometimes rhythm as } \\
\text { expressive elements (e.g., short } \\
\text { and long vowels) } \\
\text { - Memory requirement: keeping } \\
\text { previous syllables and words in } \\
\text { memory in order to combine } \\
\text { them into coherent words and } \\
\text { sentences }\end{array}$} \\
\hline
\end{tabular}


Transfer effects from musical training to speech perception and neural processing of speech signals

When a skill acquired in a specific domain has an influence on processes in another, unrelated domain, a transfer has occurred. Based on several observations, it was hypothesized that there can be a transfer from musical practice to language, more specifically, to speech processing (Kraus and Chandrasekaran, 2010; Besson et al., 2011; Patel, 2011, 2014). First, a large body of literature has shown superior auditory functions in musicians. Second, speech and music share similarities. Both of them include the processing of acoustic cues such as timbre, pitch, duration, and intensity, and involve sound sequences that are in a structured fashion unfolding in time. Third, there is an overlap of subcortical and cortical brain structures for music and speech processing (Koelsch et al., 2005; Schön et al., 2010), suggesting that they have shared neural resources (Patel, 2011, 2014).

Phoneme awareness is one of the most frequently used measures of speech perception in studies of transfer effects of musical training (Anvari et al., 2002). Linnavalli et al. (2018) used a block-randomized intervention design where language skills were followed up for two years in four separate measurement sessions, including both testing of language skills and ERP measurements of children's brain responses to changes in speech sounds. They found that even though the children's speech perception skills advanced on average, attending musical play school during the follow-up period advanced the skills even faster.

There are several other studies in which participating in a music programme was found to advance language skills. Degé and Schwarzer (2011) found strong transfer from musical training to phonological awareness in German 6-year-olds. Gromko (2005) found clear effects of 4-month music instruction on phoneme segmentation fluency in American 5-6-year-old children. Thomson et al. (2013) found strong effects on phonological awareness in British 9-year-olds, who participated in musical rhythmic training. Myant et al. (2008) showed positive effects on reading ability in British 4-year-olds, who participated in musical activity in nursery. Register (2004) found better early literacy skills in American 5-6-year-olds after different types of video and audio music programmes. Bolduc and Lefebvre (2012) found increased phonological awareness in French 5-year-olds who took part in a music programme. Chobert et al. $(2011,2014)$ found effects at the level of syllables. Clearly weaker effects of musical training have also been reported. For example, Cogo-Moreira et al. (2013), Herrera et al. (2011) and Yazejian and Peisner- 
Feinberg (2009) found small or even contrary effects of musical training on phoneme awareness in their studies in Brazilian, Spanish, and American children. It should be noted that the number of participants in these three last studies was not small, altogether 472 children. Overall, musical training in children is accompanied by positive effects on phoneme awareness in most studies, but not all.

Rhyming is a frequently used task in testing the effects of musical training on language skills. Moritz et al. (2013) used a rhyming discrimination task and found effects of musical training. Similarly, Herrera et al. (2011) found effects of musical training on rhyming tasks in two languages, and the results of Moreno et al. (2011) and Thomson et al. (2013) were very similar. In contrast, Yazejian and Peisner-Feinberg (2009) and Myant et al. (2008) found very small or even contrary effects on rhyme recognition.

There are also studies showing transfer effects from musical training to reading skills. Moreno et al. (2009) found clear effects of musical training on non-word reading skills. Similar findings but with smaller effects were found by Cogo-Moreira et al. (2013) and Herrera et al. (2011) on wordreading, and Register (2004) and Gromko (2005) on letter naming. In conclusion, many intervention and follow-up studies show positive effects of musical training on several language-related skills at varying levels from the very low-level skills like perception all the way to higher-level skills like reading, but the findings are not consistent and may depend on the age of the children, the type of musical training, and the language characteristics. Some correlational studies with Finnish learners show similar findings (Milovanov et al., 2008, 2009), thus further supporting the connection.

\section{4} Music in special education

Using music in early childhood education has a long tradition in many countries. In Finland, musical play schools are well structured and the activities are organized mainly by professional early childhood music educators with a Master's degree, and musical activities during early childhood education are considered important. Teachers know that music is also a great method for other subjects like reading and mathematics for $1^{\text {st }}$ and $2^{\text {nd }}$ grade students (Ruokonen, 2016; Rantala, 2017). Musical methods of teaching native and foreign language skills are important and effective for all learners, but they are especially important for learners with language-learning problems, since musical activities were shown to 
develop several key skills in speech perception, including speech segmentation (Francois et al., 2013).

There are several groups of special learners whose responses to different types of musical interventions have been studied, and there are even some promises for very early interventions (Virtala \& Partanen, 2018). In high-quality research, the protocol would include randomizing children into groups of interventions or waiting-list control groups, documenting the intervention, and testing prior to and after the intervention for changes in cognitive and/or academic skills. Unfortunately, not all intervention studies in music adhere to these requirements, and there are some critical voices about the field in terms of publication bias (Rothstein et al., 2005) and applicability in healthy children (Tervaniemi et al., 2018). There are, however, several groups of special learners for whom the results of intervention studies are especially important for educators.

In a large training program in at-risk communities, several benefits of musical training to language skills were found (Kraus et al., 2014a,b). Music intervention holds promise in alleviating a range of problems in, for example, the autism spectrum (Su Maw and Haga, 2018), attention deficit and hyperactivity disorder (Rickson, 2006), and developmental languagerelated dysfunctions, such as dyslexia (Habib et al., 2016). Next, we will review studies on the influence of music intervention in children with dyslexia and hearing-impairment as examples.

\subsection{Children with dyslexia}

Dyslexia is one of the most common neurodevelopmental disorders (prevalence 5-10\%; Snowling \& Melby-Lervåg 2016), which can be devastating for the individual, first in the challenge of learning to read and then learning by reading. The early negative learning experiences and feelings of inferiority compared to peers can also lead to low learning motivation. Therefore, it is of high importance to find efficient means to alleviate dyslexia and particularly to prevent it with interventions applied before school entrance. All teachers encounter learners with dyslexia during their career due to its high prevalence.

For the development of language and literacy skills, phonological awareness was proposed to be crucial (Ramus, 2013; Serniclaes et al., 2004). Phonological perception is based on speech-sound categorization ability on the basis of very short timing differences, which are challenging for dyslexic children (Serniclaes et al., 2004). Although many perceptual dysfunctions are associated with dyslexia, phonological deficits were 
suggested to be its major cause (Snowling and Melby-Lervåg, 2016; Ramus, 2014).

Overy (2003) was among the first in determining the efficacy of music intervention in children with dyslexia. The results, albeit obtained with a small group size $(\mathrm{N}=9)$ and lacking a proper matched-control group, were promising. They showed that rhythmic training improves phonological awareness and spelling skills in children with dyslexia. A study with an intervention group $(\mathrm{N}=114)$ and a control group without intervention $(\mathrm{N}=121)$, both having reading difficulties, corroborated these results (Cogo-Moreira et al., 2013). Interventions included musical improvisation, composition, and interpretation. It was found that this training improved both literacy skills and educational achievement in children with dyslexia (Cogo-Moreira et al., 2013).

A training method called Cognitive Musical Training (CMT) was also found to have a positive influence on dyslexic children (Habib et al., 2016). It has auditory exercises in duration, pitch, tempo, rhythm, and pulsation, motor exercises (e.g., tapping on rhythm), and cross-modal tasks. This intervention program was found to significantly improve the perception of phoneme categories and temporal speech components in dyslexic children. Furthermore, it enhanced auditory attention, phonological awareness (syllable fusion), reading abilities, and repetition of pseudowords.

Phonological deficits in dyslexic children were proposed to be linked to misalignments between maximum speech-signal amplitudes and fluctuations in neuronal excitability in the auditory areas (Power et al., 2013). Consistent with this view, adult dyslexic musicians were found to outperform non-musician dyslexic individuals in temporal auditory processing tests, particularly in those assessing processing of "rise time" and temporal envelope (Bishop-Liebler et al., 2014). Moreover, dyslexic musicians were found to be better than dyslexic non-musicians in tests of reading skills and phonological awareness.

Corroborating this, rhythm perception and production tasks and performance on a metric perception task predicted phonological processing and both reading accuracy and speed in dyslexic individuals (Flaugnacco et al., 2014). Some further evidence for the beneficial effects of music, particularly rhythmic training, was found by Slater et al. (2013). They determined the influence of 1 year of musical training focusing on the perception of rhythm (tapping in synchrony with a given tempo), pitch, and improvisation in 8-year-old children who were at risk for learning disability. This training was found to yield beneficial effects on 
performance in a synchrony tapping task, in which the children who underwent the training had better skills than matched controls.

Moreover, rhythmic stimuli were found to have a rapid influence on performance in a language task (Przybylski et al., 2013). Reading- and language-impaired children were presented with a rhythmic prime (a sequence of notes played either regularly or irregularly), which was immediately followed by a syntactically correct or incorrect spoken sentence (e.g., "John has/have forgotten his violin"). The regular compared with irregular rhythmic primes clearly resulted in better performance in the syntactic task.

The influence of music intervention on dyslexia has also been determined at the neural level. ERPs to syllables and changes in their voice onset time, vowel duration, and vowel frequency were recorded from dyslexic children before and after training that included either learning to play various instruments or painting exercises (Frey et al., 2019). It was found that neural discrimination of the voice onset time and vowel duration changes improved in the musical training group but not in children who did painting exercises.

The results presented above are consistent with the observations of scientists, teachers, and clinicians that music has a positive influence on basic scholarly skills. This might result from the partly overlapping neural network processing speech and music (Friederici et al., 2003; Tillman et al., 2003). Additionally, the improving influence of music on mood and brain's reward system (Sihvonen et al., 2017) can be expected to facilitate these effects.

\subsection{Hearing-impaired children}

One group of children who need specific support for their auditory functions is children with a hearing impairment. Even children who were born deaf can be helped by inserting cochlear implants $(\mathrm{Cl})$ in their inner ear. $\mathrm{Cl}$ has proven to be very successful in allowing these individuals to communicate with speech. Yet, these children have difficulties in acquiring spoken language skills due to many of them having, for example, a limited receptive and expressive vocabulary (Percy-Smith et al. 2013; Lund 2016). Children with $\mathrm{Cl}$ often experience difficulties when listening to speech in noisy conditions. Furthermore, around half of children with $\mathrm{Cls}$ have poor expressive syntactic, morphological, and narrative production skills (Boons et al. 2013), as well as phonological awareness and verbal IQ (for a review, see van Wieringen \& Wouters 2015).

According to recent evidence, music can positively influence a wide range of language-related skills in children with $\mathrm{Cl}$. This was evident in a 
study collecting questionnaire data on musical activities, particularly singing, and assessing language skills in 5-13 year-old children with $\mathrm{Cl}$ or normal hearing (Torppa et al., 2020). The language skills tested were verbal intelligence, phonological awareness, word finding performance, and perception of stress in words and sentences. It was found that musically active children with Cls performed comparably to normalhearing controls in all language tasks in these tests, whereas the performance of those who were not musically active was poorer and they made more errors in phonological and semantic word finding tasks than normal-hearing controls.

Rhythmic priming, which has been shown to enhance speech perception (Cason and Schön, 2012), was found to improve language production in children with Cls. In a study determining the effect of rhythmic priming on phonological production, children with hearing aids were asked to repeat sentences which did or did not follow a rhythmic prime (Cason et al., 2015). The rhythmic prime either matched or did not match the stress contrasts (i.e., meter) of the sentence. It was found that the children had a better phonological accuracy in producing sentences in the matching than mismatching conditions. These results imply that musical rhythmic priming enhances phonological production in children with $\mathrm{Cl}$.

Speech hearing for individuals with $\mathrm{Cl}$ is particularly challenging in noise, which is ubiquitous in modern city environments. Noise may be present in classrooms and particularly in kindergartens, making learning and interaction with teachers and peers difficult. Music can alleviate this problem as well. It was found that children who regularly sang at home had a better perception of speech in noise as compared with children who had less musical activity (Torppa et al., 2018). This study also illuminated neural correlates of these functions by finding that in the regularly singing group, a higher accuracy in speech in noise perception was associated with faster P3a ERP responses to sound changes (Torppa et al., 2018). Besides showing the beneficial effects of music activities on perceiving speech in noisy conditions, these results suggest that the improved speech in noise perception of the children who sang is associated with better attention-shifting mechanisms. Generally, the use of music is recommended in the lives of children with $\mathrm{Cls}$ both as a hobby and as a teaching method (Torppa and Huotilainen, 2019). 
For decades, teachers have used the close connection between speech and music both at the acoustic level and in emotional expressions (see Figure 1). The recent evidence highlighting these connections and showing transfer effects between musical training, use of music as a teaching method, and learning of native and foreign language skills further strengthens this connection and can make the use of music more specific and goal-driven in different learning situations and for different types of learners.

One important field of music intervention applications is learning and language disorders, such as dyslexia and in children with hearing problems. These children have challenges in developing sufficient language skills, which are the fundamental basis for any learning of knowledge at school. Both children with dyslexia and those with hearing deficits need support for the building blocks of speech: accurate perception of its acoustic features. Therefore, music, which facilitates the brain's overall plasticity through a wide neural network involving reward and learning systems (Sihvonen et al., 2017), and specifically stimulates the auditory system, is a feasible means to support language development in these groups.

Beneficial influences of music on dyslexic and hearing-impaired pupils have been shown both by correlational and intervention studies. Many teachers enjoy music, and this may motivate them to use music in their teaching. In the professional use of music in education, however, teachers should not only rely on such personal likes and dislikes but should base their choice of teaching methods on scientific evidence. Critical thinking towards any oversimplified and overoptimistic views on using music in education is needed (Tervaniemi et al., 2018). For example, short-term improvements in some test results after music listening have been misinterpreted to reflect long-term and broad beneficial changes in any cognitive or mental abilities, including intelligence. At the same time, more well-controlled comparative studies on the use of musical vs. other teaching methods are needed for different subject matters. When requiring teachers to base their teaching methods on scientific evidence it should be noted, however, that researchers should put effort on translating their findings to actionable knowledge appropriate for guiding teachers' professional practices.

Teacher training is one of the key factors affecting the use of music in education. For teachers, growth mindset is of crucial importance, 
highlighted by using phrases like "don't know yet" instead of a deterministic belief of being incompetent (Tirri \& Kuusisto, 2019). Growth mindset, and taking neural plasticity seriously, is also needed in the teachers' own musical training and learning to use music as a method of teaching. Previously, training of early childhood education teachers contained a lot of artistic work and musical training. When the training was moved to universities, the amount of musical training unfortunately decreased. In their training, the scientific understanding on why music is important in early childhood education was brought up, which is important, but practical skills are also needed in order for teachers to feel competent using music in their work in early childhood education, as well as to continue their own learning in the field of music. The same holds partially true for school teacher education. Teacher training should both educate future teachers on the reasons music is so important for learning and also how it can practically be used in everyday educational contexts. In addition, class teacher training should give the motivation and the means for all teachers to develop their own musical skills throughout their career.

There is enough evidence to say that music is a powerful resource that can advance learning (Tervaniemi et al., 2018). Good teachers are aware of the possibilities of music for helping their pupils learn different subject matter and exercise growth mindset. They are inspired by new research in educational sciences and they experiment with music interventions in their daily teaching in order to find the best ways of using music for each learner that they work with. They use music not only as content of education, but also a means of education.

\section{References}

Anvari, S. H., Trainor, L. J., Woodside, J., \& Levy, B. A. (2002). Relations among musical skills, phonological processing, and early reading ability in preschool children. Journal of Experimental Child Psychology, 83, 111-130. doi: 10.1016/S0022-0965(02)00124-8

Besson, M., Chobert, J., \& Marie, C. (2011). Transfer of training between music and speech: common processing, attention, and memory. Frontiers in Psychology, 2, 94.

Bermudez, P., Lerch, J. P., Evans, A. C., Zatorre, R. J. (2009). Neuroanatomical correlates of musicianship as revealed by cortical thickness and voxel-based morphometry. Cerebral Cortex, 19, 1583-1596.

Bishop-Liebler, P., Welch, G., Huss, M., Thomson, J. M., \& Goswami, U. (2014). Auditory temporal processing skills in musicians with dyslexia. Dyslexia, 20, 261279. doi: $10.1002 /$ dys.1479 
Bolduc, J., \& Lefebvre, P. (2012). Using nursery rhymes to foster phonological and musical processing skills in kindergarteners. Creative Education, 3, 495-502. doi: 10.4236/ce.2012.34075

Boons T., De Raeve L., Langereis M., et al. (2013). Expressive vocabulary, morphology, syntax and narrative skills in profoundly deaf children after early cochlear implantation. Research in Developmental Disabilities, 34, 2008-2022.

Cason, N., Hidalgo, C., Isoard, F., Roman, S., \& Schön, D. (2015). Rhythmic priming enhances speech production abilities: evidence from prelingually deaf children. Neuropsychology, 29, 102-107. doi: 10.1037/neu00 00115

Cason, N., \& Schön, D. (2012). Rhythmic priming enhances the phonological processing of speech. Neuropsychologia, 50, 2652-2658. doi: 10.1016/j.neuropsychologia.2012.07.018

Chobert, J., Francois, C., Velay, J. L., \& Besson, M. (2014). Twelve months of active musical training in 8- to 10-year-old children enhances the preattentive processing of syllabic duration and voice onset time. Cerebral Cortex, 24, 956967. doi: $10.1093 /$ cercor/bhs377

Chobert, J., Marie, C., Francois, C., Schön, D., \& Besson, M. (2011). Enhanced passive and active processing of syllables in musician children. Journal of Cognitive Neuroscience, 23, 3874-3887. doi: 10.1162/jocn_a_00088

Cogo-Moreira, H., Brandão de Ávila, C. R., Ploubidis, G. B., \& Mari, J. D. J. (2013). Effectiveness of music education for the improvement of reading skills and academic achievement in young poor readers: a pragmatic cluster-randomized, controlled clinical trial. PLOS ONE, 8, 59984. doi: 10.1371/journal.pone.0059984 Degé, F., \& Schwarzer, G. (2011). The effect of a music program on phonological awareness in preschoolers. Frontiers in Psychology, 2, 124 . doi: 10.3389/fpsyg.2011.00124

Dweck, C. S. (2006). Mindset: The New Psychology of Success. New York, NY: Random House.

Flaugnacco, E., Lopez, L., Terribili, C., Zoia, S., Buda, S., Tilli, S., et al. (2014). Rhythm perception and production predict reading abilities in developmental dyslexia. Frontiers in Human Neuroscience, 8, 392 . doi: 10.3389/fnhum.2014.00392

François, C., Chobert, J., Besson, M., \& Schön, D. (2013). Music training for the development of speech segmentation. Cerebral Cortex, 23, 2038-2043.

Frey, A., Francois, C., Chobert, J., Velay, J. L., Habib, M., \& Besson, M. (2019). Music training positively influences the preattentive perception of voice onset time in children with dyslexia: a longitudinal study. Brain Science, 9, 91

Friederici, A. D., Rüschemeyer, S. A., Hahne, A., Fiebach, C. J. (2003). The role of left inferior frontal and superior temporal cortex in sentence comprehension: localizing syntactic and semantic processes. Cerebral Cortex, 13, 170-177. 
Galván, A. (2010). Neural plasticity of development and learning. Human brain mapping, 31(6), 879-890.

Gromko, J. E. (2005). The effect of music instruction on phonemic awareness in beginning readers. Journal of Research in Music Education, 53, 199-209. doi: 10.1177/002242940505300302

Habib, M., Lardy, C., Desiles, T., Commeiras, C., Chobert, J., \& Besson, M. (2016). Music and dyslexia: A new musical training method to improve reading and related disorders. Frontiers in Psychology, 7, 22.

Hannon, E. E., Snyder, J. S., Eerola, T., \& Krumhansl, C. L. (2004). The role of melodic and temporal cues in perceiving musical meter. Journal in Experimental Psychology and Human Perception and Performance, 30, 956-974

Herrera, L., Lorenzo, O., Defior, S., Fernandez-Smith, G., \& Costa-Giomi, E. (2011). Effects of phonological and musical training on the reading readiness of nativeand foreign-Spanish-speaking children. Psychology of Music, 39, 68-81. doi: 10.1177/0305735610361995

Kimppa, L., Shtyrov, Y., Partanen, E., \& Kujala, T. (2018). Impaired neural mechanism for online novel word acquisition in dyslexic children. Scientific Reports, 8, 12779. doi:10.1038/s41598-018-31211-0

Koelsch, S., Gunter, T. C., Wittfoth, M., \& Sammler, D. (2005). Interaction between syntax processing in language and in music: an ERP study. Journal in Cognitive Neuroscience, 17, 1565-1577.

Kraus, N., \& Chandrasekaran, B. (2010). Music training for the development of auditory skills. Nature Reviews in Neuroscience, 11, 599-605. doi: $10.1038 / \mathrm{nrn} 2882$

Kraus, N., Slater, J., Thompson, E. C., Hornickel, J., Strait, D. L., Nicol, T., et al. (2014a). Auditory learning through active engagement with sound: biological impact of community music lessons in at-risk children. Frontiers in Neuroscience, 8, 351. doi: 10.3389/fnins.2014.00351

Kraus, N., Slater, J., Thompson, E. C., Hornickel, J., Strait, D. L., Nicol, T., et al. (2014b). Music enrichment programs improve the neural encoding of speech in at-risk children. Journal of Neuroscience, 34, 11913-11918. doi: 10.1523/JNEUROSCI.1881-14.2014

Lappe, C., Herholz, S. C., Trainor, L. J., Pantev, C. (2008). Cortical plasticity induced by short-term unimodal and multimodal musical training. Journal of Neuroscience, 28, 9632-9639

Linnavalli, T., Putkinen, V., Lipsanen, J., Huotilainen, M., \& Tervaniemi, M. (2018). Music playschool enhances children's linguistic skills. Scientific reports, 8, 1-10.

Lund, E. (2016). Vocabulary knowledge of children with cochlear implants: A meta-analysis. Journal of Studies in Deaf Education, 21, 107-121. 
Milovanov, R., Huotilainen, M., Välimäki, V., Esquef, P. A., \& Tervaniemi, M. (2008). Musical aptitude and second language pronunciation skills in school-aged children: Neural and behavioral evidence. Brain research, 1194, 81-89.

Milovanov, R., Huotilainen, M., Esquef, P. A., Alku, P., Välimäki, V., \& Tervaniemi, M. (2009). The role of musical aptitude and language skills in preattentive duration processing in school-aged children. Neuroscience Letters, 460, 161-165. doi: 10.1016/j.neulet.2009.05.063

Moreno, S., Friesen, D., \& Bialystok, E. (2011). Effect of music training on promoting preliteracy skills: preliminary causal evidence. Music Perception, 29, 165-172. doi: 10.1525/mp.2011.29.2.165

Moreno, S., Marques, C., Santos, A., Santos, M., Castro, S. L., \& Besson, M. (2009). Musical training influences linguistic abilities in 8-year-old children: more evidence for brain plasticity. Cerebral Cortex, 19, 712-723. doi: 10.1093/cercor/bhn120

Moritz, C., Yampolsky, S., Papadelis, G., Thomson, J., \& Wolf, M. (2013). Links between early rhythm skills, musical training, and phonological awareness. Reading and Writing, 26, 739-769. doi: 10.1007/s11145-012-9389-0

Myant, M., Armstrong, W., \& Healy, N. (2008). Can music make a difference? A small scale longitudinal study into the effects of music instruction in nursery on later reading ability. Educational Child Psychology, 25, 83-100.

Overy, K. (2003). Dyslexia and music: from timing deficits to musical intervention. Annals of New York Academy of Sciences, 999, 497-505. doi: 10.1196/annals.1284.060

Patel, A. D. (2007). Music, language, and the brain. Oxford: Oxford UP.

Patel, A. D. (2011). Why would musical training benefit the neural encoding of speech? The OPERA hypothesis. Frontiers in Psychology, 2, 142. doi: 10.3389/fpsyg.2011.00142

Patel, A. D., Peretz, I., Tramo, M., Labreque, R. (1998). Processing prosodic and musical patterns: a neuropsychological investigation. Brain and Language, 61, 123- 144

Patel, A. D. (2014). Can nonlinguistic musical training change the way the brain processes speech? The expanded OPERA hypothesis. Hearing Research, 308, 98108. doi: 10.1016/j.heares.2013.08.011

Percy-Smith, L., Busch, G., Sandahl, M., et al. (2013). Language understanding and vocabulary of early cochlear implanted children. International Journal of Pediatric Otorhinolaryngology, 77, 184-188.

Peretz, I., Vuvan, D., Lagrois, M. É., \& Armony, J. L. (2015). Neural overlap in processing music and speech. Philosophical Transactions of the Royal Society of London B: Biological Sciences, 370, 20140090. doi: 10.1098/rstb.2014.0090 
Power, A. J., Mead, N., Barnes, L., \& Goswami, U. (2013). Neural entrainment to rhythmic speech in children with dyslexia. Frontiers in Human Neuroscience, 7, 777. doi: $10.3389 /$ fnhum.2013.00777

Przybylski, L., Bedoin, N., Krifi-Papoz, S., Herbillon, V., Roch, D., Léculier, L., et al. (2013). Rhythmic auditory stimulation influences syntactic processing in children with developmental language disorders. Neuropsychology, 27,121-131. doi: 10.1037/a0031277

Ramus, F., Marshall, C. R., Rosen, S., \& van der Lely, H. K. (2013). Phonological deficits in specific language impairment and developmental dyslexia: towards a multidimensional model. Brain, 136, 630-645.

Ramus, F. (2014). Neuroimaging sheds new light on the phonological deficit in dyslexia. Trends in cognitive sciences, 18(6), 274-275.

Rantala, E. (2017). Musiikki opetuksen eheyttäjänä: luokanopettajien kokemuksia ja käsityksiä oppiainerajat ylittävästä musiikinopetuksesta alkuopetuksessa. Pro gradu -tutkimus, Jyväskylän yliopisto.

Rickard, N. S., Toukhsati, S. R., \& Field, S. E. (2005). The effect of music on cognitive performance: Insight from neurobiological and animal studies. Behavioral and Cognitive Neuroscience Reviews, 4, 235-261. https://doi.org/10.1177/1534582305285869

Rickson, D. J. (2006). Instructional and improvisational models of music therapy with adolescents who have attention deficit hyperactivity disorder (ADHD): A comparison of the effects on motor impulsivity. Journal of Music Therapy, 43, 3962.

Register, D. (2004). The effects of live music groups versus an educational children's television program on the emergent literacy of young children. Journal of Music Therapy, 41, 2-27. doi: 10.1093/jmt/41.1.2

Rogalsky, C., Hickok, G. (2010). The role of Broca's area in sentence comprehension. Journal in Cognitive Neuroscience,. doi:10.1162/jocn.2010.21530.

Rothstein, H. R., Sutton, A. J., \& Borenstein, M. (2005). Publication bias in metaanalysis. John Wiley \& Sons.

Ruokonen, I. (2016). Esi-ja alkuopetuksen musiikin didaktiikka. Finn Lectura.

Schneider, P., Scherg, M., Dosch, H. G., Specht, H. J., Gutschalk, A., Rupp, A. (2002). Morphology of Heschl's gyrus reflects enhanced activation in the auditory cortex of musicians. Nature Neuroscience, 5, 688-694

Schön, D., Gordon, R., Campagne, A., Magne, C., Astesano, C., Anton, J. L., \& Besson, M. (2010). Similar cerebral networks in language, music and song perception. Neurolmage, 51, 450-461.

Serniclaes, W., Van Heghe, S., Mousty, P., Carre, R., \& Sprenger-Charolles, L. (2004). Allophonic mode of speech perception in dyslexia. Journal of Experimental Child Psychology, 87, 336-61 
Shtyrov, Y., Nikulin, V., \& Pulvermüller, F. (2010). Rapid cortical plasticity underlying novel word learning. Journal of Neuroscience, 30, 16864-16867. DOI: https://doi.org/10.1523/JNEUROSCI.1376-10.2010

Sihvonen, A.J., Särkämö, T., Leo, V., Tervaniemi, M., Altenmüller, E., \& Soinila, S. (2017). Music-based interventions in neurological rehabilitation. Lancet Neurology, 16, 648-660. doi:10.1016/S1474-4422(17)30168-0

Slater, J., Tierney, A., \& Kraus, N. (2013). At-risk elementary school children with one year of classroom music instruction are better at keeping a beat. PLOS ONE, 8, e7725. doi: 10.1371/journal.pone.0077250

Snowling, M. J., \& Melby-Lervåg, M. (2016). Oral language deficits in familial dyslexia: A meta-analysis and review. Psychological Bulletin, 142, 498.

Maw, S. S., \& Haga, C. (2018). Effectiveness of cognitive, developmental, and behavioural interventions for Autism Spectrum Disorder in preschool-aged children: A systematic review and meta-analysis. Heliyon, 4(9), e00763.

Tervaniemi, M., Tao, S., \& Huotilainen, M. (2018). Promises of music it education?. In Frontiers in Education, 3, 74.

Thomson, J. M., Leong, V., \& Goswami, U. (2013). Auditory processing interventions and developmental dyslexia: a comparison of phonemic and rhythmic approaches. Reading and Writing, 26, 139-161. doi: 10.1007/s11145012-9359-6

Tillmann, B., Janata, P., Bharucha, J. J. (2003). Activation of the inferior frontal cortex in musical priming. Brain Research Cognitive Brain Research, 16, 145-161. Tirri, K. \& Kuusisto, E. (2019). Opettajan ammattietiikkaa oppimassa. Gaudeamus.

Torppa, R., Faulkner, A., Laasonen, M., Lipsanen, J., \& Sammler, D. (2020). Linkłs of prosodic stress perception and musical activities to language skills of children with Cochlear Implants and normal hearing. Ear and Hearing, 41, 395-410.

Torppa, R., Faulkner, A. Kujala, T., Huotilainen, M., \& Lipsanen, J. (2018). Developmental links between speech perception in noise, singing, and cortical processing of music in children with cochlear implants. Music Perception, 36, 156-174.

Torppa, R., \& Huotilainen, M. (2019). Why and how music can be used to rehabilitate and develop speech and language skills in hearing-impaired children. Hearing Research, 380, 108-122.

Toiviainen, P., Krumhansl, C. L. (2003). Measuring and modeling real-time responses to music: the dynamics of tonality induction. Perception, 32, 741-766. van Wieringen A. \& Wouters J. (2015). What can we expect of normallydeveloping children implanted at a young age with respect to their auditory, linguistic and cognitive skills? Hearing Research, 322, 171-179. 
Virtala, P., \& Partanen, E. (2018). Can very early music interventions promote atrisk infants' development? Annals of the New York Academy of Sciences, Blackwell Publishing Inc. https://doi.org/10.1111/nyas.13646

Wong, P. C. M., Skoe, E., Russo, N. M., Dees, T. Kraus, N. (2007). Musical experience shapes human brainstem encoding of linguistic pitch patterns. Nature Neuroscience, 10, 420-422.

Yazejian, N., \& Peisner-Feinberg, E. S. (2009). Effects of a preschool music and movement curriculum on children's language skills. NHSA Dialogues, 12, 327341. doi: 10.1080/15240750903075255

Zatorre, R. J., Belin, P., \& Penhune, V. B. (2002). Structure and function of auditory cortex: music and speech. Trends in Cognitive Sciences, 6, 37-46. 